\title{
Eat and run: anoxic feeding and subsequent aerobic recovery by Orchomene obtusus in Saanich Inlet, British Columbia, Canada
}

\author{
Alex De Robertis ${ }^{1, *}$, Ketil Eiane ${ }^{2}$, Greg H. Rau $^{3}$ \\ ${ }^{1}$ Scripps Institution of Oceanography, 8602 La Jolla Shores Drive, La Jolla California 92037-0208, USA \\ ${ }^{2}$ The University Courses on Svalbard, 9171 Longyearbyen, Norway, \\ ${ }^{3}$ Institute of Marine Sciences, University of California, Santa Cruz, California 95064, USA
}

\begin{abstract}
The lysianassid amphipod Orchomene obtusus (Sars) is known as an epibenthic scavenger, but it is abundant in the water column of Saanich Inlet, British Columbia, a temperate fjord with poorly oxygenated deep water. Sampling with vertically-stratified nets and baited traps indicates that $O$. obtusus is abundant within the oxycline at 100 to $140 \mathrm{~m}$, is present in anoxic deep waters at low abundances, and is also abundant in the anoxic benthic environment. Shipboard incubations revealed that $O$. obtusus can survive between 10 and $33 \mathrm{~h}$ of anoxia at in situ conditions. Stable isotope and gut fluorescence measurements suggest that these amphipods feed on material produced in surface waters, and not on the isotopically dissimilar suspended detrital material present in the vicinity of the oxycline. The amphipods do not enter surface waters, and it appears that $O$. obtusus has adapted to oxygen gradients in this environment by feeding on surface-water-derived material in the food-rich and predator-poor anoxic benthos and subsequently migrating into the water column to conduct aerobic respiration. These vertical excursions are probably a modification of the swimming behavior exhibited by hyperbenthic amphipods in well-oxygenated environments, and may constitute an important mechanism for benthic-pelagic coupling.
\end{abstract}

KEY WORDS: Orchomene obtusus $\cdot$ Amphipoda $\cdot$ Anoxia $\cdot$ Benthic-pelagic coupling $\cdot$ Vertical migration $\cdot{ }^{13} \mathrm{C} \cdot{ }^{15} \mathrm{~N}$

\section{INTRODUCTION}

Saanich Inlet, British Columbia, exhibits intermittent periods of anoxia due to a shallow entrance sill which restricts deep-water circulation (Herlinveaux 1962). The oxygen deficiency in this fjord exerts a strong influence on the community structure and spatial distribution of both benthic (Tunnicliffe 1981) and pelagic (Mackie \& Mills 1983) organisms. In Saanich Inlet, the lysianassid amphipod Orchomene obtusus (Sars) (see Barnard 1964 for synonymies) is abundant in the water column in regions of low oxygen concentration (Bary et al. 1962, Mackie \& Mills 1983). The distribution of $O$. obtusus overlaps with a mid-water layer of flocculent

${ }^{*}$ Present address: NWFSC/NMFS, Hatfield Marine Science Center, 2030 S. Marine Science Drive, Newport, Oregon 97365, USA. E-mail: aderobertis@ucsd.edu suspended particles in the oxycline (Mackie \& Mills 1983). Some zooplankton in poorly oxygenated environments are known to consume detrital organic aggregates containing large numbers of associated bacteria in the vicinity of the oxycline (Gowing \& Wishner 1992), and O. obtusus may feed on this midwater layer of particulate matter.

The presence of this species $100 \mathrm{~m}$ above the bottom in this locality is rather surprising, as the genus Orchomene is generally not an important component of zooplankton assemblages. Rather, in more typical oxygenated environments, lysianassid amphipods are conspicuous members of the hyperbenthos, or demersal community, scavenging in association with the bottom (Ingram \& Hessler 1983, Mees \& Jones 1997, Tamburri \& Barry 1999). O. obtusus is typical of this group as it is specialized for episodic carrion feeding, possessing well-developed aesthetascs on the first 
antenna for chemosensory detection of odor plumes, a modified digestive system allowing for storage of large volumes of food, and is tolerant of extended periods of starvation (Dahl 1979, Kaufmann 1994, Tamburri \& Barry 1999).

In this study, we consider the vertical distribution of Orchomene obtusus in this environment of steep oxygen gradients in the context of its respiratory physiology and feeding ecology. We explore 2 possibilities that might explain its distribution. O. obtusus may forage in the anoxic benthos, scavenging carrion and particulate matter which have sedimented from surface waters, and then migrate into oxic waters for aerobic respiration. Alternatively, this amphipod may feed on the suspended detrital material in midwater in the vicinity of the oxycline, while maintaining aerobic respiration.

\section{METHODS}

The water column distribution of Orchomene obtusus (Sars) was determined through verticallystratified net sampling at noon and midnight (6 vertical series in 1996, 7 vertical series in 1997) using a $1 \mathrm{~m}^{2}$ MOCNESS (Wiebe et al. 1985) equipped with $333 \mu \mathrm{m}-$ mesh nets. $\mathrm{CTD}-\mathrm{O}_{2}$ profiles were made in the vicinity of the MOCNESS station $\left(48^{\circ} 34.4^{\prime} \mathrm{N}, 123^{\circ} 30.4^{\prime} \mathrm{W}\right)$, which had a bottom depth of $225 \mathrm{~m}$. In 1997 the CTD was equipped with a beam transmissometer. In both years the oxygen sensor measurements agreed well with Winkler titrations made as calibration measurements (mean discrepancy $=0.16 \mathrm{ml} \mathrm{l}^{-1}$ ). Vertical profiles of chlorophyll a ( $\mathrm{chl}$ a) and pheopigment fluorescence of material retained on $\mathrm{GF} / \mathrm{F}$ filters were analyzed in both years.

In 1997 a vertical array of 9 baited traps was deployed at this station to assess the presence of Orchomene obtusus near the bottom as well as in the hypoxic and anoxic parts of the water column. Traps were $25 \mathrm{~cm}$ long, $10 \mathrm{~cm}$ diameter PVC cylinders with $333 \mu \mathrm{m}$ mesh attached to the bottom, and an inverted entrance cone at the top that reduced the diameter to $1.5 \mathrm{~cm}$. The traps were attached to a positivelybuoyant polypropylene line at a series of distances $(0,1,2.5,10,25,50,75,100,125 \mathrm{~m})$ from the sea floor. Traps were baited with either canned cat food or with both cat food and a sardine allowed to age on deck for $24 \mathrm{~h}$. In both cases the traps were deployed for $3 \mathrm{~h}$, from 16:00 to 19:00 h.

The tolerance of Orchomene obtusus to anoxia was evaluated by incubating the amphipods in gas-tight $345 \mathrm{ml}$ bottles containing anoxic water collected from $175 \mathrm{~m}$ depth using water bottles mounted on the CTD rosette. A strong hydrogen sulfide odor was detectable in water samples from deeper than $150 \mathrm{~m}$, which is consistent with previous sampling of the anoxic portions of this inlet (Anderson 1983). Experimental individuals were collected from the water column with a plankton net and incubated in filtered oxic water at $9^{\circ} \mathrm{C}$ for $24 \mathrm{~h}$ prior to the experiment. One group of amphipods was fed euphausiid and amphipod fecal pellets $1 \mathrm{~h}$ prior to the experiment. Groups of $3 \mathrm{O}$. obtusus were added to the bottles in $10 \mathrm{ml}$ of water. The bottles were flushed with $>700 \mathrm{ml}$ of anoxic water, and then rapidly capped to minimize the diffusion of oxygen into the water. In control incubations, fed $O$. obtusus were transferred into bottles and oxygenated water was added in the same manner. For both treatment and controls, 9 bottles were incubated in the dark at $9^{\circ} \mathrm{C}$, the in situ deep-water temperature. Preliminary experiments revealed that amphipods could survive $10 \mathrm{~h}$ of anoxia with negligible mortality, and that amphipods that had stopped beating their pleopods had died and could not be revived by incubation in oxic water. Based on these preliminary results, survivorship in the bottles was assessed by exposure time until death, as estimated by the termination of pleopod movement. The number of individuals surviving in each bottle was recorded every $1 \mathrm{~h}$ after an initial $10 \mathrm{~h}$ incubation.

To assess the diet of Orchomene obtusus, and determine where in the water column they feed, likely sources of suspended food particles were examined using several techniques. The gut contents of amphipods $(\mathrm{n}=21$ ) collected from 150 to $100 \mathrm{~m}$ on the night of 12 August 1996 were examined with a compound microscope. Gut fluorescence measurements were made on $O$. obtusus to determine wether the amphipods ingested material containing chlorophyll. $O$. obtusus of 8 to $10 \mathrm{~mm}$ body length were collected from the 125 to $100 \mathrm{~m}$ abundance maximum during the day (26 July 1997) and night (12 August 1996, 26 July 1997) and stored in liquid $\mathrm{N}_{2}$ until analysis. Individuals were homogenized in $90 \%$ acetone with an ultrasonicator, extracted for $1 \mathrm{~h}$ and then centrifuged. The supernatant was analyzed with a calibrated Turner Designs Model 10 fluorometer. Chl $a$ and pheopigments were summed to give total pigment, which was corrected for background tissue fluorescence of $O$. obtusus $(\mathrm{n}=19)$ starved for $37 \mathrm{~h}$ in filtered seawater. No correction was made for possible degradation of chlorophyll to nonfluorescent compounds within amphipod guts (Goericke et al. 2000).

Measurements of ${ }^{13} \mathrm{C}:{ }^{12} \mathrm{C}$ and ${ }^{15} \mathrm{~N}:{ }^{14} \mathrm{~N}$ ratios were made on individual amphipods collected in 1996 and immediately frozen in liquid $\mathrm{N}_{2}$. The isotopic values of Orchomene obtusus collected from 150 to $125 \mathrm{~m}$ depth at night were compared to those of the euphausiid Euphausia pacifica captured in the 0 to $20 \mathrm{~m}$ stratum. 
The isotopic composition of suspended particulate matter (SPM) from near-surface $(0.3751$ filtered from $4,6,8,10,12,14,16,18 \mathrm{~m}$ depth) and deep water $(0.75 \mathrm{l}$ filtered from 80, 83, 86, 89, 110, 120, $130 \mathrm{~m}$ depth) retained on a pre-ashed $\mathrm{GF} / \mathrm{F}$ filter was also measured. Samples were analyzed for ${ }^{13} \mathrm{C} /{ }^{12} \mathrm{C}$ and ${ }^{15} \mathrm{~N} /{ }^{14} \mathrm{~N}$ and these ratios were converted to conventional $\delta$ notation using the methods described in Rau et al. $(1989,1990)$. The amount of SPM retained on the filters was not sufficient to allow $\delta^{15} \mathrm{~N}$ determinations.

\section{RESULTS}

The depth-stratified zooplankton sampling indicated that in both years Orchomene obtusus was numerically abundant in the plankton, with vertical abundance maxima typically between 100 and 125 m (Fig. 1A,B). At these depths the oxygen concentrations were in the range of 0.2 to $1.5 \mathrm{ml} \mathrm{l}^{-1}$. Increased turbidity detected by the beam transmissometer in 1997 (Fig. 2A), as well as the discoloration of filters in vertical series of water filtrations in both years, indicated that there was a midwater layer of particulate matter at depths of 80 to $140 \mathrm{~m}$. This layer exhibited low chl a (mean \pm SD; 1996: 0.19 $\pm 0.02 \mu \mathrm{g}$

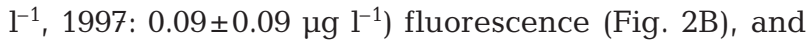

overlapped with the abundance maximum of $O$. obtusus. The distribution of pheopigments mirrored that of chl $a$ and was low between 80 and 140 m (mean \pm SD; 1996: $0.84 \pm 0.05 \mu \mathrm{g} \mathrm{l}^{-1}$, 1997: $0.17 \pm 0.15 \mu \mathrm{g} \mathrm{l}^{-1}$ ). The number of $O$. obtusus present in the water column was similar near noon and midnight. In 1996, there appeared to be a slight broadening of the vertical distribution during the night, but the amphipods did not enter the surface waters where phytoplankton was abundant. O. obtusus was also consistently present throughout the anoxic deep waters at abundances of $\sim 0.5 \mathrm{~m}^{-3}$ in both years, and was the only species captured at these depths. O. obtusus captured in anoxic strata were alive and active upon recovery.

Deployment of the vertical trap array in 1997 revealed that Orchomene obtusus was abundant on the bottom. Large numbers of $O$. obtusus were captured in traps on the sediment surface, while no amphipods were captured in traps suspended just $1 \mathrm{~m}$ above the bottom (Fig. 1C). Amphipods were trapped in lesser numbers at $125 \mathrm{~m}$ depth, which corresponds to the water column abundance maximum. O. obtusus was the only species found in the traps and all specimens were recovered alive and intact, with no signs of damage or cannibalism. It was clear from the condition of the recovered bait in the bottom traps that the amphipods were actively ingesting the bait.

During incubations in anoxic water, amphipods were actively crawling or swimming within the bottles. After $10 \mathrm{~h}$ amphipods in the anoxic treatments began to die, and all amphipods died within $33 \mathrm{~h}$ (Fig. 3). Mortality in the oxic control was $7 \%$ after $34 \mathrm{~h}$ incubation. The exposure time for $50 \%$ mortality in anoxic incubations was approximately 20 to 21 h. Because amphipods incubated within a bottle can not be considered as independent samples, the time until the first individual in a bottle died was used for the purpose of statistical testing. Time until mortality defined in this manner was significantly longer in the oxic control than in the anoxic incubations, but was not statistically different for fed and unfed individuals in the anoxic treatments (Kruskal-
Fig 1. Orchomene obtusus. Vertical distribution in relation to dissolved oxygen concentration; amphipods were sampled in the water column with a vertically stratified net system on (A) 10 to 13 August 1996 and (B) 23 to 30 July 1997; oxygen profiles are shown for reference; $(\bullet)$ series near midnight; (O) daytime series. (C) Amphipods recovered in vertical trap array deployed on July 30 to 311997 


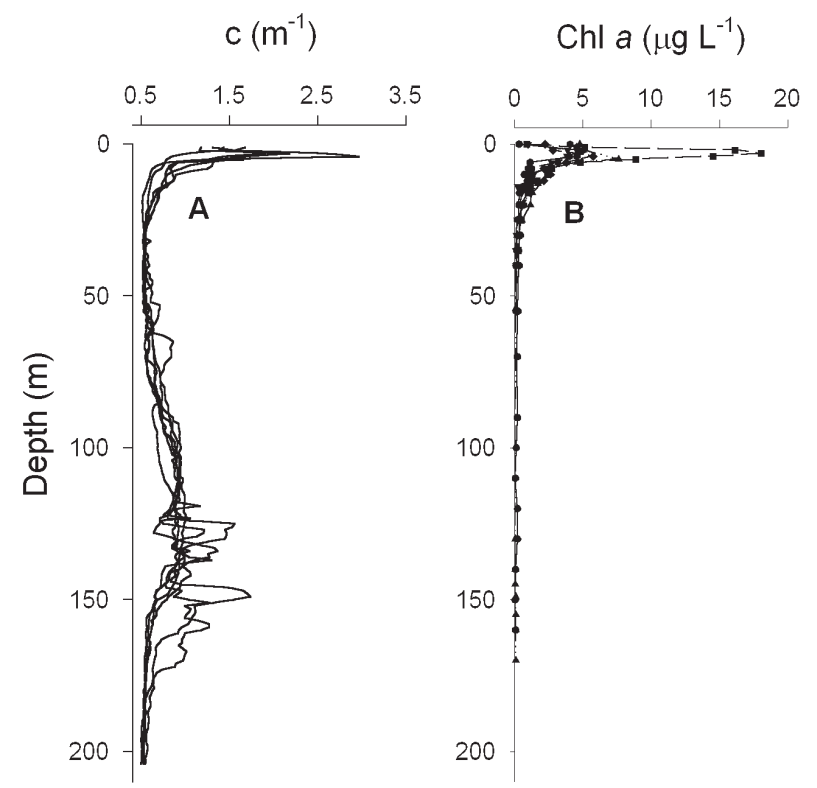

Fig. 2. Vertical profiles of (A) beam attenuation coefficient (c) at $660 \mathrm{~nm}$ (6 casts between 25 July and 1 August 1997), and (B) extracted chlorophyll a (2 casts $>150 \mathrm{~m}$ and 4 casts $<60 \mathrm{~m}$ between 25 and 31 July 1997). Vertical stratification of chlorophyll was similar in 1996, but absolute concentrations were up to 2 times higher in the upper $10 \mathrm{~m}$

Wallis test, $\mathrm{H}_{\mathrm{df}=2}=18.18, \mathrm{p}<0.001$, Nemenyi a posteriori procedure). A replicate experiment in which the environmental chamber failed and temperatures rose to $15^{\circ} \mathrm{C}$ yielded similar qualitative results (data not shown), although time until mortality was considerably shorter ( $4 \%$ control mortality, $50 \%$ mortality in $\sim 10 \mathrm{~h}$ for anoxic treatments).

Orchomene obtusus contained amorphous greenishbrown material in their guts, which we were unable to

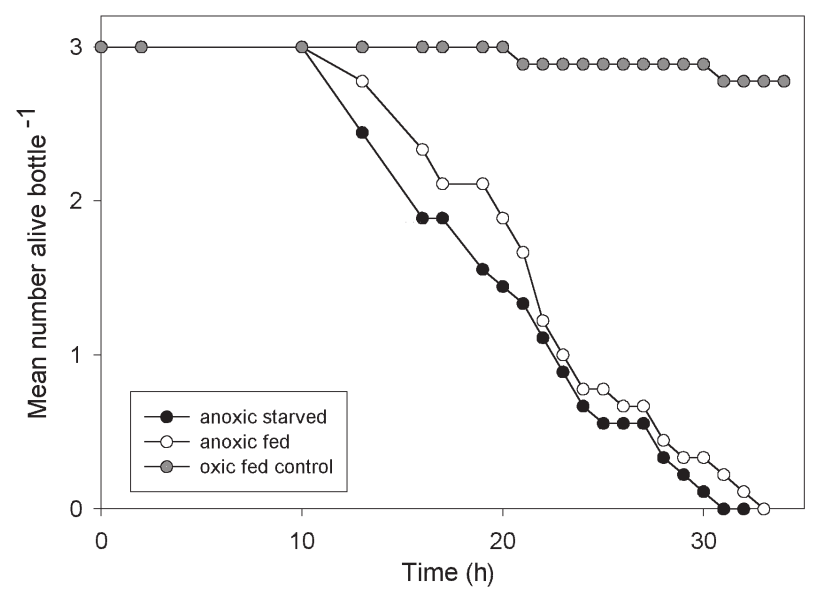

Fig. 3. Orchomene obtusus. Mean survival during anoxic and oxic (control) incubations. Amphipods in controls and 1 series of anoxic treatments were fed prior to incubation, and another series of amphipods in anoxic incubations was starved. Nine groups of 3 amphipods were incubated in each treatment identify microscopically. The gut fluorescence analyses indicated that $O$. obtusus were actively ingesting material derived from phytoplankton in both 1996 and 1997: median (95\% CI) ng pigment amphipod ${ }^{-1}$ for 1996 night $=80.32$ (53.47 to 136.90$), \mathrm{n}=52$; for 1997 day $=54.4$ (8.23 to 69.20$), \mathrm{n}=24$; for 1997 night $=39.52$ (20.21 to $77.07), \mathrm{n}=23$ ). Although gut fluorescence varied significantly between all samples, differences between sampling dates or diel differences could not be identified in pairwise comparisons (Kruskal-Wallis test, $\mathrm{H}_{\mathrm{df}}=2=$ $6.28, \mathrm{p}<0.05$, Nemenyi a posteriori procedure).

The stable isotope analyses revealed that the $\delta^{13} \mathrm{C}$ of Orchomene obtusus is similar to that of both surfacewater SPM and Euphausia pacifica (Fig. 4A). The median $\delta^{13} \mathrm{C}$ of $O$ obtusus, E. pacifica and surface water SPM cannot be distinguished statistically, but all are significantly higher than the median $\delta^{13} \mathrm{C}$ of oxycline SPM (Kruskal-Wallis test, $\mathrm{H}_{\mathrm{df}=3}=19.97, \mathrm{p}<0.001$, Nemenyi a posteriori procedure). The $\delta^{15} \mathrm{~N}$ of $O$. obtusus is more variable, and is significantly higher than the $\delta^{15} \mathrm{~N}$ of E. pacifica (Mann-Whitney $U$-test, $U_{7,6}$ $=37, \mathrm{p}<0.05)$ (Fig. 4B).

\section{DISCUSSION}

Together, the results of net sampling and trapping indicate that, in Saanich Inlet, Orhomene obtusus is present in the oxycline region, throughout the anoxic portion of the water column, and on the bottom. Submersible observers in this location have previously documented the presence of amphipods on and near the bottom during periods of water column anoxia (Mackie \& Mills 1983). The trap deployments indicate that the amphipods are present at high densities on the bottom and are readily attracted to and consume bait, suggesting that $O$. obtusus is actively foraging in association with the bottom. The lack of $O$. obtusus in traps only $1 \mathrm{~m}$ above the bottom is consistent with trapping in other environments, suggesting that $O$. obtusus is primarily active at distances of $<1 \mathrm{~m}$ above the bottom (Christiansen \& Diel-Christiansen 1993).

The laboratory incubations demonstrate that Orchomene obtusus is capable of routinely withstanding anoxia for periods of up to $12 \mathrm{~h}$. In our experiments, exposure to fecal pellet food did not affect survivorship, although previous work has shown that amphipod respiration can increase dramatically for extended periods after brief exposure to food odors (Smith \& Baldwin 1982). It is not clear if this discrepancy is due to the use of different food or is due to interspecific differences. Overall, our results compare favorably to in situ incubations of $O$. obtusus in Saanich Inlet, in which $10 \%$ of individuals survived $27 \mathrm{~h}$ of incubation at $185 \mathrm{~m}$ (Liu 1989). 
On the basis of these results, we infer that those amphipods present on the bottom must leave the anoxic bottom waters at least once each day and ascend into oxygenated regions of the water column in order to recover from anaerobic respiration. From an energetic perspective, anaerobic metabolism in anoxic deep waters is inefficient: crustaceans rely primarily on lactate fermentation for anaerobic metabolism (Zebe 1991), which is 12 to 13 fold less efficient in terms of ATP/unit substrate than aerobic oxidative metabolism (Hochachka \& Somero 1984). Crustaceans respond to anaerobiasis by postexposure increases in aerobic respiration above the routine metabolic rate. During this recovery period, cellular constituents are returned to steady state: the ATP and phosphagen pools are built back up, and cells are detoxified-for example by removal of sulfide if present, and acidic end-products of anaerobic metabolism (Ellington 1983, Hochachka \& Somero 1984). During this time, a portion of the lactate is probably reoxidized to glucose for use in aerobic metabolism (Vismann \& Hagerman 1996). Although the net energetic cost of anaerobiasis for Orchomene obtusus in the presence of hydrogen sulfide is not known, it is highly unlikely that this metabolic inefficiency is overcome by energetic savings associated with a potential reduction in activity when on the bottom (Vismann \& Hagerman 1996).

The $\delta^{13} \mathrm{C}$ of surface particulate matter is within the range expected for SPM derived primarily from phytoplankton material previously reported for plankton and SPM in this location (Cowie et al. 1992, Nakatsuka et al. 1992). The depleted $\delta^{13} \mathrm{C}$ of the SPM in the vicinity of the oxycline points towards a terrestrial origin, as it is similar to the $\delta^{13} \mathrm{C}$ of -25.5 for marine detritus derived from Pacific Northwest vascular plants (Hedges \& Mann 1979). A non-marine origin for the deep SPM is also consistent with the profiles of phytoplankton pigments, which do not indicate an increase in fluorescence associated with this layer. Detritus of terrestrial origin is refractory (Cowie et al. 1992), and is likely to be a poor food source for Orchomene obtusus.

Both the $\delta^{13} \mathrm{C}$ and gut fluorescence measurements suggest that the diet of Orchomene obtusus is primarily of near-surface origin. Since the $\delta^{13} \mathrm{C}$ of zooplankton tissue reflects the $\delta^{13} \mathrm{C}$ of the animals long-term food source within $\sim 1$ to $2 \%$ (e.g. Macko et al. 1982, Checkley \& Entzeroth 1985), the isotopic composition of the amphipods is consistent with a diet derived from surface waters, but not from feeding on suspended particulates in deep waters. The similarity of $O$. $o b$ tusus $\delta^{13} \mathrm{C}$ to that of the euphausiid Euphausia pacifica, which is largely herbivorous (Ohman 1984) but can ingest marine snow (Dilling et al. 1998), further suggests that the amphipods are not feeding on the midwater particulates. The gut fluorescence analyses of
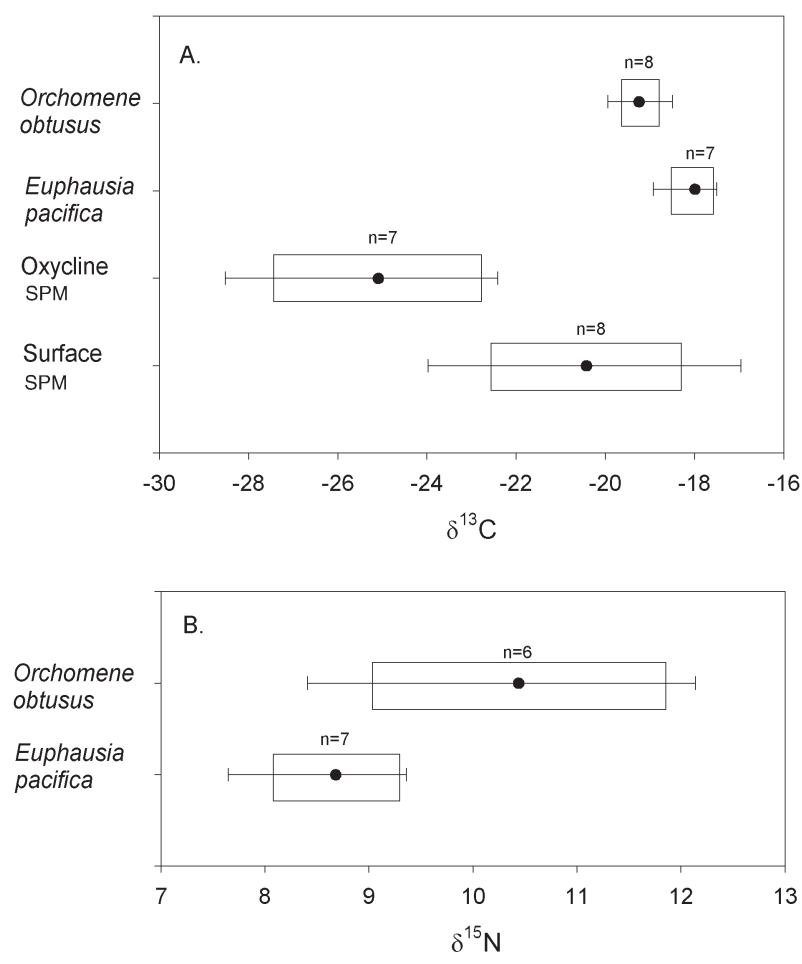

Fig. 4. Orchomene obtusus and Euphausia pacifica. Stable isotope analyses. (A) $\delta^{13} \mathrm{C}$ measurements values for near-surface suspended particulate matter (SPM), and SPM from the oxycline region are also shown; . (B) $\delta^{15} \mathrm{~N}$ measurements. Horizontal lines indicate ranges, rectangles $\pm 1 \mathrm{SD}$, and circles means.

The number of measurements is indicated in each case

amphipods collected in the vicinity of the oxycline indicate recent ingestion of material containing phytoplankton pigments, although the SPM in this location contains very little pigment. Since the amphipods did not enter surface waters in our 13 vertically stratified net profiles, we infer that they are feeding on surfacederived material that has sedimented to the benthos. The sediment composition in Saanich Inlet supports this inference, as the sediment has a $\delta^{13} \mathrm{C}$ of -21.15 , is of a predominately marine origin with a small terrestrial component, and is organic-rich, containing a large amount of diatom frustules and fecal pellets (Sancetta 1989, Cowie et al. 1992).

The average $\delta^{15} \mathrm{~N}$ of Orchomene obtusus is $\sim 1.8 \%$ higher than that of the primarily herbivorous Euphausia pacifica. Since zooplankton $\delta^{15} \mathrm{~N}$ usually increases as higher trophic level food sources are utilized (e.g. Macko et al. 1982, Checkley \& Entzeroth 1985), the relative $\delta^{15} \mathrm{~N}$ elevation in $O$. obtusus is consistent with its scavenging on detritus and carrion. It is unlikely that $O$. obtusus feeds as a carnivore in the plankton to any extent, since although it is an efficient scavenger, it does not respond to odors of live prey or consume live prey in the laboratory (Liu 1989, Tamburri \& Barry 1999). 
The ability to exploit the anoxic benthos confers 2 potential advantages, which may more than offset the energetic costs of anaerobic metabolism. First, spending time in anoxic and hypoxic waters should reduce predation risk, particularly from fishes which are strongly selective for large-bodied and opaque prey such as Orchomene obtusus but avoid anoxic water (Mees \& Jones 1997, Nestlerode \& Diaz 1998). Second, the benthos is likely to represent a concentrated food source, as the sustained anoxia in bottom waters reduces the degradation rate of deposited organic material (Hartnett et al. 1998). In addition, the anoxic bottom water eliminates other epibenthic macrofauna (Tunnicliffe 1981, Diaz \& Rosenberg 1995), that are potential competitors of $O$. obtusus for carrion and detritus deposited on the substrate.

Although the behavior of Orchomene obtusus in Saanich Inlet may appear surprising, it is consistent with the behavior of amphipods in more typical oxic environments. Hyperbenthic amphipods are generally found on the substrate or within a few meters of the bottom, often making small-amplitude diel vertical migrations (Kaartvedt 1986). Some species are strong swimmers, and a small fraction of the population can be sampled well off the bottom (Ingram \& Hessler 1983, Sainte-Marie \& Brunel 1985). It appears that in Saanich Inlet, $O$. obtusus has increased both the frequency and amplitude of its vertical excursions into the water column in response to environmental hypoxia. This enables it to feed in the organic-rich anoxic benthic environment and subsequently migrate into more oxygenated waters to recover from periods of anaerobic metabolism. Periodic access to the benthos appears to have enabled $O$. obtusus to exploit the advantageous combination of a release from competition, an abundant food supply, and an escape from predation in this habitat, which would explain the high local biomass of O. obtusus in Saanich Inlet.

The deep-water feeding of this population of Orchomene obtusus is vertically displaced from the site of subsequent aerobic respiration in the water column. If excretion and defecation also occur higher in the aerobic portion of the water column, this would provide an example of carbon and nutrient transport that is counter to the more typical net downward transport of material by zooplankton through gravitational settling or diel vertical migration (Longhurst \& Harrison 1989). In Saanich Inlet, O. obtusus are consumed by fishes in the oxic parts of the water column (Bary et al. 1962), thus directly linking material consumed in the anoxic benthos to the pelagic food web. The benthic substrate is unlikely to be accessible to other planktonic organisms in the system during periods of water column anoxia. Thus, the feeding excursions undertaken by $O$. obtusus are likely to be an important mechanism for transporting sedimentary organic matter to pelagic food chains during periods of extreme hypoxia in Saanich Inlet. The standing stock of O. obtusus is considerable in Saanich Inlet (Fig. 1), and this process may be of significance for primary and/or secondary production. This is not a unique circumstance: in oligotrophic lakes, vertically migrating amphipods that scavenge in the benthos and subsequently release nutrients into surface waters have been identified as a major mechanism for nutrient recycling (Wilhelm et al. 1999). Although the importance of the proposed mechanism for benthic-pelagic coupling in Saanich Inlet cannot be quantified from the current study, the subject warrants further research.

Acknowledgements. We are indebted to C. Staude for assistance with amphipod identification, to A. Bridgeman for help in the field, to D. B. Field for discussion, and to M. D. Ohman for his support of all aspects of this work. A.D.R. was partially supported by a NSF graduate fellowship, and K.E. by fellowships from the Norwegian Research Council. G.H.R. thanks D. J. Des Marais for the use of analytical facilities at NASAAmes Research Center. Supported by the US National Science foundation (OCE 94-21876, 96-18626, 97-11369, and 00-02725).

\section{LITERATURE CITED}

Anderson JJ (1983) The oxic-anoxic interface in Saanich Inlet. Can Tech Rep Hydr Ocean Sci 38:18-23

Barnard JL (1964) Marine Amphipoda of Bahia De San Quintin, Baja California. Pac Nat 4:1-138

Bary BM, Barraclough WE, Herlinveaux R (1962) Scattering of underwater sound in Saanich Inlet, British Columbia. Nature (Lond) 194:36-37

Checkley DM, Entzeroth LC (1985) Elemental and isotopic fractionation of carbon and nitrogen by marine planktonic copepods and implications to the marine nitrogen cycle. J Plankton Res 7:553-568

Christiansen B, Diel-Christiansen S (1993) Respiration of lysianassoid amphipods in a subarctic fjord and some implications on their feeding ecology. Sarsia 78:8-15

Cowie GL, Hedges JI, Calvert SE (1992) Sources and relative reactivities of amino acids, neutral sugars, and lignin in an intermittently anoxic marine environment. Geochim Cosmochim Acta 56:1693-1978

Dahl E (1979) Deep-sea carrion feeding amphipods: Evolutionary patterns in niche adaptation. Oikos 33:167-175

Diaz RJ, Rosenberg R (1995) Marine benthic hypoxia: a review of its ecological effects and the behavioral responses of benthic macrofauna. Oceanogr Mar Biol Annu Rev 33: 245-303

Dilling L, Wilson J, Steinberg D, Alldredge A (1998) Feeding by the euphausiid Euphausia pacifica and the copepod Calanus pacificus on marine snow. Mar Ecol Prog Ser 170: 189-201

Ellington WR (1983) The recovery from anaerobic metabolism in invertebrates. J Exp Zool 228:431-444

Goericke R, Strom SL, Bell MA (2000) Distribution and sources of cyclic pheophorbides in the marine environment. Limnol Oceanogr 45:200-211

Gowing MM, Wishner KF (1992) Feeding ecology of bentho- 
pelagic zooplankton on an eastern tropical Pacific seamount. Mar Biol 112:451-467

Hartnett HE, Keil RG, Hedges JI, Devol AH (1998) Influence of oxygen exposure time on organic carbon preservation in continental margin sediments. Nature (Lond) 391: 572-574

Hedges JI, Mann DC (1979) The lignin geochemistry of marine sediments from the southern Washington Coast. Geochim Cosmochim Acta 43:1008-1809

Herlinveaux RH (1962) Oceanography of Saanich Inlet in Vancouver Island, British Columbia. J Fish Res Board Can 19:1-37

Hochachka PW, Somero GN (1984) Biochemical adaptation. Princeton University Press, NJ

Ingram CL, Hessler RR (1983) Distribution and behavior of scavenging amphipods. Deep-Sea Res 30:683-706

Kaartvedt S (1986) Diel activity patterns in deep living cumaceans and amphipods. Mar Ecol Prog Ser 30:243-249

Kaufmann RS (1994) Structure and function of chemoreceptors in scavenging lysianassoid amphipods. J Crustac Biol 14:54-71

Liu Q (1989) Ecophysiological studies of Orchomeniopsis affinis (Holmes) (Lysianassidae Amphipoda) in an intermittently anoxic fjord. MS thesis, University of Victoria, Victoria, British Columbia

Longhurst AR, Harrison WG (1989) The biological pump: profiles of plankton production and consumption in the upper ocean. Progr Oceanogr 22:47-123

Mackie GO, Mills CE (1983) Use of the Pisces IV submersible for zooplankton studies in coastal waters of British Columbia. Can J Fish Aquat Sci 40:763-775

Macko SA, Lee WY, Parker PL (1982) Nitrogen and carbon isotope fractionation by two species of marine amphipods: Laboratory and field studies. J Mar Biol Ecol 63:145-149

Mees J, Jones MB (1997) The hyperbenthos. Oceanogr Mar Biol Annu Rev 35:221-255

Nakatsuka T, Handa N, Wada E, Wong CS (1992) The dynamic changes of stable isotopic ratios of carbon and nitrogen in suspended and sedimented particulate organic matter during a phytoplankton bloom. J Mar Sci 50: $267-296$

Nestlerode JA, Diaz RJ (1998) Effects of periodic environmen-

Editorial responsibility: Otto Kinne (Editor),

Oldendorf/Luhe, Germany tal hypoxia on predation of a tethered polychaete, Glycera americana: implications for trophic dynamics. Mar Ecol Prog Ser 172:185-195

Ohman MD (1984) Omnivory by Euphausia pacifica: the role of copepod prey. Mar Ecol Prog Ser 19:125-131

Rau GH, Heyraud M, Cherry RD (1989) ${ }^{15} \mathrm{~N} /{ }^{14} \mathrm{~N}$ and ${ }^{13} \mathrm{C} /{ }^{12} \mathrm{C}$ in mesopelagic shrimp from the northeast Atlantic Ocean: evidence for differences in diet. Deep-Sea Res 36: 1103-1110

Rau GH, Tessie JL, Rassoulzadegan F, Fowler SW (1990) ${ }^{13} \mathrm{C} /{ }^{12} \mathrm{C}$ and ${ }^{15} \mathrm{~N} /{ }^{14} \mathrm{~N}$ variations among size-fractionated marine particles: implications for their origin and trophic relationships. Mar Ecol Prog Ser 59:33-38

Sainte-Marie B, Brunel P (1985) Suprabenthic gradients of swimming activity by cold-water gammaridean amphipod crustacea over a muddy shelf in the Gulf of Saint Lawrence. Mar Ecol Prog Ser 23:57-69

Sancetta C (1989) Sediment transport by fecal pellets in British Columbian fjords. Mar Geol 89:331-346

Smith KL, Baldwin RJ (1982) Scavenging deep-sea amphipods: effects of food odor on oxygen consumption and a proposed metabolic strategy. Mar Biol 68:287-298

Tamburri MN, Barry JP (1999) Adaptations for scavenging by three diverse bathyal species, Eptatretus stouti, Neptunea amianta and Orchomene obtusus. Deep-Sea Res Part I 46: 2079-2093

Tunnicliffe V (1981) High species diversity and abundance of the epibenthic community in an oxygen-deficient basin. Nature (Lond) 294:354-356

Vismann B, Hagerman L (1996) Recovery from hypoxia with and without sulfide in Saduria entomon: oxygen debt, reduced sulfur and anaerobic metabolites. Mar Ecol Prog Ser 143:131-139

Wiebe PH, Morton AW, Bradley AM, Backus RH, Craddock JE, Barber V, Cowles TJ, Flierl GR (1985) New developments in the MOCNESS, an apparatus for sampling zooplankton and micronekton. Mar Biol 87:313-323

Wilhelm FM, Hudson JJ, Schindler DW (1999) Contribution of Gammarus lacustris to phosphorus recycling in a fishless alpine lake. Can J Fish Aquat Sci 56:1679-1686

Zebe E (1991) Arthropods. In: Bryant C (ed) Metazoan life without oxygen. Chapman \& Hall, London, p 218-237

Submitted: September 14, 2000; Accepted: January 9, 2001 Proofs received from author(s): August 20, 2001 